\title{
Some aspects of teaching the technology of designing and planning information systems in health care
}

\author{
LÁSZLÓ DARAGÓ
}

\begin{abstract}
In this article, we use the well-known ideas of technology in designing of new information systems in health care. We explain the principle that "making a health care application" "is more than writing a program", "it requires a strong co-operation and continuous contact" between the system analysts and users. The concept of the information system must contain the work of the whole system, which means that the planning and designing process should focus on the services, which really support the customer's functions. It has to be compatible with the earlier information systems based on several decade's experience. In this paper we use the most important elements of system theory. First of all we explain why it is important to take into account the behaviour of those, who operate the information system, and also their habits and way of thinking when planning then information system. We emphasise that it is importance to overview the whole information system and its functionality because it is a major aspect of the system planning.

This paper can be used in university courses especially in teaching SDM, SSADM, Martin, etc. technologies for information system analysts, program designers and programmers.
\end{abstract}

Key words and phrases: information system documentation, user requirements, health care application, teaching information system planning, information systems.

ZDM Subject Classification: Q59. 


\section{Introduction}

In Hungary, several information system planning methods have been developed since the early $70 \mathrm{~s}$. The experience of decades in information system planning, programming and implementing shows that the approach to the information system design should be supported by the opinion of the operating personnel. There is a pressure suppliers on the market from the side of to use always the newest system platform and it's possibilities. Some companies who were among the firsts which introduced a given PC desktop later found that some components are compatible neither down nor up to former and later versions. These applications may contain uniform algorithms, well tested system solutions, but they ignore the individual properties of the companies, which apply them. The users can hardly decide, whether the installed information system is suitable to support their daily routine or not. The lack of money and time also influence them in this direction. This means that the company always has an instantaneous solution but this can never be the optimal one, which fits the characteristics of the company. In most cases, the users are not involved in the process of the information system planning, so they face and meet the ready information system when it is finished.

Below we give some examples, when there were methodologies, but no technology was known or used. We mention four information systems, which were implemented in Hungary in different health care institutions.

A. A county hospital won a World Bank financed tender to adopt and implement the basics of a Finnish hospital information system. Their application was targeted on, how to get experience in adopting systems from EU-15 countries, and whether these systems can be introduced or not in the Hungarian hospital structure. During the implementation process the Finnish supplier and management of the hospital could not agree, concerning some legal aspects. Finally, the original supplier left the project, and the hospital inherited all rights on the adopted information system. The greediness also arose as a circumstance. The hospital thought of developing a Hungarian software product with its own resources. They had programmers, but no information system analysts, they could not allocate even the hardware and software resources on the right places, and could not even realise the real needs of the hospital.

The staff of this hospital tried to develop its own information system, including programming. They thought that their resources and experience would be enough for such an activity, moreover, for supporting the hospital information system generally. 
They failed. Neither their resources were marketable at system analysis nor information technology. They finally produced something, but it was far from the system dreamed off. They spent much more time and money on the development process, than if they had bought it. And of course, they could never sell a copy of it.

Their system did not meet the requirements of the rules which will be described in Section 2, that is they did not consider their own capabilities in introducing the Finnish system.

B. Several EU-countries adopted the same, so called integrated company level managing, producing and computing software. The software is very useful and applicable at managing, financing and evaluating. About $60 \%$ of the Hungarian domestic manufacturing and trade companies apply this information system.

The problem usually arises, when the company has not defined in a written form its requirements. It does not have a complete system plan on the primary functions marking the activities of the profile of the company, but economical reasons, business considerations or other constraints force the company to install a system to cover the secondary functions. Without knowing the real needs of the whole company established for a well-defined activity, the secondary functions that is mainly the booking activity will be changed according to the purchased system. The Hungarian hospitals are owned by the state or self-government. Thus, the booking system of a private company is not applicable for them.

The real danger is that later the primary activities must be compatible with the secondary functions, that is, structure and philosophy of the purchased software. The process of financing thus the financial information systems too usually can not be easily adopted in different countries. The main reason for this is that the different countries have different taxation systems. A serious problem that can arise is that after the preparations of the implementation of this system because different reasons (e.g. criminal reasons) may be blocked the consolidation process. There are no complete specifications on the real needs, which could define what requirements should an another product perform in order to substitute the original one.

They did not take into account the advice, which will be described in Section 3, that is the external circumstances under which the information system must work. 
C. The performance based health financing system - widely named $\mathrm{DRG}^{1}$ or Casemix system, - requires to record every inpatient and outpatient cases. The finance system needs data to identify the patient, it's insurance status and other properties of the care, and the data for calculating the hospital income. Formerly, when the hospitals were financed by input financing system, there did not exist complete data collection on the inpatient and outpatient cases on individual level. By introducing the DRG system a departmental case level complete data collecting and servicing system has been realised. However the hospital can not realise its income for the case, unless fulfilling and forwarding the necessary data. Some hospitals and governmental organisations consider this data collecting system "gold mine". This can be true, but only if we want to study the financing system, and nothing else.

When ministerial or scientific researches tried to use this database for morbidity or mortality studies, the results were distorted. The reason was obvious, the data suppliers were "economically motivated", they recorded the codes, which resulted more income to the hospital.

When some hospitals tried to use this data collecting system, they could not introduce the $\mathrm{EHR}^{2}$, because only the $\mathrm{MBDS}^{3}$ was recorded. The Electronic Health Patient Record should be used to describe data related to the patient from the hospital admission till the discharge. All reports of the hospital events are generated from the EHR. The Minimum Basic Data Set contains only the common part of the data describing the different types of hospital cases. The form and content are independent from the type of hospital department. The aim of using this data set is to collect and transfer the insurance and financial data. The hospitals get their income by through this data collecting system.

The conclusion from this example is, that the information systems have been planned and built for a well defined target, generally they should not be used for other goals too.

Hospitals ignored paying attention to the domain requirements, which will be described in Section 4, that is, that data for a specialist are different from the ones which are used in finance.

D. One of companies dialysis centres network operating a used a company wide uniform system in all centres in Hungary. It provides this service in about

${ }^{1}$ Diagnoses Related Groups

${ }^{2}$ Electronic Health Patient Record

${ }^{3}$ Minimum Basic Data Set 
$14 \mathrm{EU}$ and non-EU countries as well, and all the national sub-networks of centres were linked to the central booking system. Once, someone in the management thought of including besides the economical system the uniform clinical system too. They planned to select a good overall system via tenders, and install it on all the workstations of all the countries, while the server is in the headquarter of the company, somewhere in Germany. The work started in summer of 2001 and it was planned to change the existing clinical systems and to install the overall framework by 1st January, 2002.

They ignored, that while the diseases are coded uniform way by the $\mathrm{ICD}^{4}$, the medical activities are not uniform, every country uses its own classification systems. The MBDS is also different in different countries - even inside the EU.

The last information is, that they will introduce the overall system from the beginning of 2006 .

They did not take into consideration the advice described in Section 4 on the importance of the different cultures that is the daily, weekly routines are different.

We would like to underline the followings:

There exist and are used different system planning methods but no technology and their importance is far less in the process of planning and designing, than it would be necessary. The experience of decades in teaching information systems show, that these methodologies are not considered very important when assembling the curricula. It should be emphasised even in education that a working information system is much more than just a program.

Most of our curricula make much account of the system administrator knowledge, the database design and maintenance and programming skills. The systems organising methods also have to have more importance a higher role at the system planning and designing.

The first step in building information system is to identify and describe the output (the requirements). The second step is to determine the needed input data. After that we create the information system's model. We decide the instruments needed for the whole information system.

Another decision which has to be taken at the very beginning of the system implementation is to decide the consolidation form of the system: purchase, self - development, leasing or outsourcing.

${ }^{4}$ International Classification for Diseases 


\section{Requirements of documentation}

The expectations about the possibilities of an information system are always very high. Understanding of the problem which has to be solved is paramount, the functionality is not defined by the demand of different users or other system demands. The services and the restrictions of the system are named requirement documentation, while the process to determine, analyse, document and check these services and restrictions is requirement planning, or Capacity Planning. Never begin to work without written documentation. It has to be stressed even in teaching, that to collect the system requirement documentation has to be the first and overall step of the system planning.

The types of requirement documentation are [1]:

- The user requirements documentation: containing expressions, what services have to be performed by the system and what the restrictions are. These are natural - or spoken - language expressions containing figures, drawings, tables, drafts and patterns. It is made by the user/procurer, and usually it takes place very beginning in the development cycle.

- The system requirements which particularise the system services and system restrictions, are also called functional specifications. The contract on the system providing between the procurer and the supplier should be based on this documentation. It is made by the provider, considering the user requirements.

- The software requirement specification is an abstract description of the software plan. It is necessary to design and produce the software and hardware. This is the basis of the particular software and hardware plan and its implementation. This specification gives additional information to the requirement documentation. The software requirements include both the system's user requirements and the detailed information system requirements. The user requirements and system requirements can co-exist in the same documentation, or the user requirements can introduce the information system requirements. In case that the requirements are numerous, the detailed requirements can be collected in an individual documentation.

For example, the software requirement specification (SRS) should perform the following assumptions [5]:

- Determine only external behaviour.

- Specify any restrictions that can prevent a successful implementation. 
- Must be easily updated.

- It can be used as reference for information system maintenance.

- It should contain forecasts for the lifecycles of the information system.

- Whenever possible predict and offer solutions to unwanted events.

\section{User requirements, information system requirements}

In the training of information system analyst students we have to explain, that not only the programming languages and techniques, but also the knowledge of modern information technology such as hypermedia, word processors, databases and object oriented techniques are very important. It is indispensable to have basics of the network technologies and components, the information system architectures, such as the client-server architecture, moreover, of the structure of the operating and maintenance system.

Besides the computer technique skills the domain knowledge is also of great importance. If these basic skills are lacking, the students will not understand the user requirements, and moreover, they surely will not be able to adopt them to the information system capabilities.

The user requirements are a user or procurer provided documentation. It is overall description of the information system services required by the user. The system requirements are the provider's answer to the user requirements, a sort of sign-off that the offered system satisfies the user demands, together with specifically defined restrictions.

These materials contain the demanded functional requirements, that is, the exact descriptions of the information system services. The functional requirements describe how the inputs determine the outputs. They do not and must not relate to the technical description of the method of the output generation. It will be the provider's duty to determine them - it is not practical to make restrictions on the internal functioning. That could lead to arguments on the responsibility in the case of non-usability of the information system or its parts.

The user requirements and system requirements contain the so-called nonfunctional requirements. These can be classified as product requirements, organisational requirements and external requirements.

The product requirements are restrictions on the behaviour of the whole software, such as response time, speed, reliability, portability or the robustness of the information system. These questions are very important because in case that 
the system cannot service a functional requirement, the system - permanently or temporarily - although with decreased functionality works. In case that some of non-functional requirement is lacking the performance of the whole system decreases. The critical non-functional requirements are considered critical because the lack of any of them leads to the non-usability of the whole system [1].

The organisational requirements originate from the user and the provider's regulations and procedures. They contain the used procedure standards and the documenting, describing or planning methods, they also contain the descriptions of the shipping and installing. The shipping contains not only the installation, but the training and education of the users of the system. It is also important to determine the warranty of the system and the description of the Hot-line and Help-desk services.

The external requirements originate from the circumstances, which are not included in the given information system and its development process. These are the co-operation with other existing systems or just the information system, which has to be changed; the environmental requirements, software and hardware compatibility restrictions e.g. it may be not easy to install a database engine on a computer, where different versions of that database engine are installed. The law regulations or ethic restrictions about the functioning of the information system are also included.

The third group of the user requirements and system requirements - which can be a separated or classified into the functional and non-functional requirements - are the domain requirements [1]. These are related to the special knowledge of the user. They do not originate from the individual claims of the user or procurer, but the knowledge, which characterises the field of the application. - For example, the information system of a dialysis centre has to correspond to the regulations of the kidney care process and also the regulations of the health finance both being independent from the demands of the users. - The domain requirements are expressed in a special language of the application field, so the information system designers often have difficulties in understanding them. The domain experts may leave out information from the domain requirements, because it seems obvious for them. But the truth is, that this is an obvious knowledge for the system designers, and it can lead to the fact, that a requirement would not properly be realised. It is very important to involve the domain expert computing professionals in the development process, in order to avoid this possibility. 


\section{The user demands and the user requirements}

During the training it has to be explained in details, that the user usually does not clearly understand the technical possibilities. Very often, they do not realise that their work process is not up-to-date. Information system analyst students have to put themselves into the user's place to understand the demands to turn them into requirements.

As we have seen above, the user requirements are a complete description of the system demand services. The existence of this documentation is the procurer's responsibility. It is not always readily available, due to the lack of information science skills of the procurer. The procurer usually employs advisors to co-operate in the writing of this documentation.

This is the reason for the appearance of a new phase. The first step is to describe the procurer's own thoughts. This documentation can be named user demands. These are the user or procurer's claims for the information system services, although it is often and full of contradictions. We should not expect correct and professional definitions of the user's requirements, because the user or procurer is not a professional in information technology. In the case of several potential users, each of them will mark its own points of view. Fundamental aspects or services can be disregarded by the functioning of the information system itself, in the case when the users are not motivated to solve them. When examining the user it is worth to mark the main aspects, which main aspects can be used to install the new information system, or change the old one. These should to have priority at defining the user requirements if compromises are necessary in order to solve contradictions [4].

Since the procurer and the user is not the same person in case of health information systems, a special group of users should be involved in the definition process of the requirements documentation. This special group is named stakeholders. They are the ones who know exactly what the daily routines are. They can mark those special aspects, which are of basic importance, however these aspects are not considered remarkable by the procurer. - It has happened, that the procurer (medical doctor) defined the data of a dialysis treatment, which have to be input during the 4-hour long treatment. However, he did not think of the fact that the nurse would have to change her gloves, or sterilise the keyboard at inputs, corresponding to the disinfecting regulations. The stake-holder (matron) realised that fact. The result was, that the software module wad made, but never used. 
To understand the user demands we must study the ethnography, that is the daily, weekly routines, the parallel or sequential done activities. This is important when defining both the functional and non-functional requirements [7], [2].

\section{The software development}

The result of the selection of the programming and running environment depends on both the organisational requirements and the external requirements. There are also third party applications running at the procurer and the new information system should not disturb their functioning. In case that these other applications are not defined, the provider is free to select the platform - within its financial or other limits. It is a common mistake to select the newest environment although there is no experience on availability and stability of the running environment or operating system [3]. Sometimes the environments, which are excellent for educational purposes because of their facilities and newness, but they are not suitable for developing and working in health care. The primary aspect is reliability, which cannot be replaced by spectacular programming solutions. The well-known - well-rehearsed environments are more popular at work. The system administrators use them with a higher degree of confidence and the maintenance and recovery is easier.

The re-usage of software components is also an argument for not to change the programming environment frequently. The tested and well-tried modules are worth to put at the disposal of other programmers of the provider. In this case it is enough to implement the earlier developed functions and procedure in the new applications instead of rewriting them. The fact, that the software components will be used at editing, compiling or running the information system, is not relevant from the point of view of the re-usage. The efficiency and effectiveness increase by the re-usage of the software components [1].

The domain specific calculations and algorithms must be easy to update. It is useful to test and calibrate the formulae and algorithms given by the stakeholders. It also frequently occurs, that the procurer's calculation methods change during the development process. We have to be prepared to modify them during the maintenance of the information system. It is an equally significant aspect to ensure the easy way of modifying the reports. The reports have to be modified because of the changes of the regulations of the external data communication, and the upgrades of the quality assurance. 
It would be advisable to look at the user's earlier applications when planning the users interface. It can be a good source of information [1].

We may modify the structure of the usual - well-learned, well-rehearsed - user surface in the least possible way. Introducing the new information system a shock for the organisation and the users. It must not be forgotten that the beneficiary of the health information systems are not the users of the applications. This means that the end-users are not definitely motivated to implement the information system.

The qualification level of the users, their general experience and practice in using information systems and the given application together determine what type of the help system should be implemented. It can be a context-sensitive help application, handbook, users guide, or a combination of them. The costs of the development are influenced by the selection of the help system too. - The handbook and users guide are suggested to be installed with the information system in several electronic file formats too. Otherwise they used to be stored in the boss' folder, which is the first step for them to disappear.

The stake-holders, of course, participate in the test of the information system. Furthermore it is worth involving in the testing process as many user types, as possible. This is important in order to detect the bugs and to overcome the user's aversion from the new information system. The users consider the information system as their own, after having participated in any phase of the development, even the testing.

\section{Maintenance}

It is typical that the system-implementing project ignores the circumstances and costs of the maintenance. The information system planning courses must contain not only the implementing work but also the training processes. It is very important to survey the qualification and the experience in using the information system at the user's company, too. It is necessary to teach how to estimate the maintenance periods, costs, staff and other resources. Students have to have to know how to manage the planned information system stops and how to prepare themselves to unwanted system fails.

It would be desirable to make the user able to install and set up the information system. (In this context the word "user" means "some of the users".) This is important in order to decrease the provider's difficulties. Besides the successful installation it increases the confidence in the information system. The user must 
be satisfied and like the system. Of course, we have to try to build in the solutions which require the least activity from the user. It is very important that the documentation of the installation and maintenance be easy to understand. The Hot-line service offers the user the feeling of safety when continuously operating the system. This service can be provided by telephone or e-mail. It should be available during the usage of the information system in order to ensure that in case of a malfunction the user can get assistance in solving the problems. Other problems can also occur if the performance is very slow. Experience show that $95 \%$ of the unwanted events during the operation can be successfully dealt with by the Hot-line service. It is very important, that the supporter must be professional of the information system at the developing level. The user realises by intuition if the supporter is not sure and this leads to increase the mistrusts [6].

The Help-desk is not only a problem recorder but also an active troubleshooter.

The technical supporter has active role in the recovering of the system stops. It can work by local or remote support. The remote support assumes Internet connection among the provider and the user machines. Big companies performing their activities in several places use to apply managed leased line (MLL).

\section{Conclusions}

It is recommended for the training of the information system planners and information system analysts to emphasise the fact that a good information system is not a guarantee for success at the market. The information system has to be not well applicable and reliable but also popular.

The system analyst students were usually a bit non convinced when they were told about the importance of involving the end-users in the planning and designing work of the information systems. They believed that professional knowledge is enough and no help is needed from amateurs at the system designing and planning. After some weeks of hospital practice they realise that only those systems are successful, the users of which are involved in the developing process. Otherwise they fail to recognise or may even deny the value of the implemented system. Students should bear in mind that an unused system has no value. The system has to be built for users and in order to assist their activity. It cannot be popular and successful without clarifying the goal itself. The process of defining the exact needs of the users is more important than it actually appears in the training process as compared to other subjects. 
The success functioning of the information system, besides the correct software and solid hardware, is based on the relation between the product and the user. This means, that indirectly the success is up to the user and the provider's relationship. The chance of the occurrence of errors have to be minimised, for example by locking the unnecessary options, keys, key-combinations - E.g. if the left shift - right control - F10 combination can freeze the information system, this combination will be found within a week after the instalment. One must also keep in mind, that in every workplace can be found amateurs, who try to find the shortcuts of the normal way operation.

Some small gifts can help to realise the developer's dream. The installed information system must be adapted to the daily routine. The information system is for the users, vice versa. It is worth to be informed about the concurrent software tools an equipment used by the user. Building in the function of these tools in the software, and make them available for pop-up access generate the user's sympathy, making the whole co-operation successful. Such kinds of pop-ups are the calendar, calculator, internal or external mailing subsystem and messaging which can communicate with the information system. Several check-listing options should set up to authorise the user's input.

\section{Acknowledgements}

I would like to thank Mátyás Arató and János Kormos for their help at working out the ideas, which has been written in this paper.

Moreover, I am grateful to Ilona Bay for correction of the English of this paper.

\section{References}

[1] Ian Sommerville, Software engineering, Addison Wesley Pub Co; 6th edition, 2000.

[2] R. H. Thayer and M. Dorfman, Recommended practice for software requirement specification, Software Requirements Engineering, IEEE Computer Society Press, 1997.

[3] Daragó László, Önellátás helyett, Computer Panoráma 99/7, 24-26.

[4] Gordon B. Davis and Margarethe H. Olson, Management information systems: Conceptual Foundations, Structure and Development, McGrow-Hill, 1987.

[5] James Martin, Cleve Finkelstein, Information Engineering, Savant Institute, England, 1981.

[6] James A. O'Brian, Introduction to information systems, Richard D. Irwin Inc., 1991. 
[7] G. Kotonya and I. Sommerville, Requirements Engineering: Processes and Techniques, Wiley, 1998.

LÁSZLÓ DARAGÓ

HEALTH COLLEGE FACULTY

UNIVERSITY OF DEBRECEN

H-4400 NYÍREGYHÁZA, SÓSTÓI ÚT 2.

HUNGARY

E-mail: darago1@axelero.hu

(Received September, 2004) 